\title{
Research on the Application of Emotional Design in Cultural Creative Product Design
}

\author{
Yajing Hou \\ Art and Design Department, Nanjing Institute of Technology, Nanjing, Jiangsu, 211167, China
}

\begin{abstract}
In recent years, cultural creative products as an important branch of cultural creative industries, have been widespread concern and promotion. It is not only a cultural heritage, but also the crystallization of the wisdom of designers, and it is one of the important means of cultural heritage and spread. The creative design is the interpretation of cultural heritage and the refinement of cultural spirit, and it needs to combine the characteristics of the present era and the series of cultural re-design activities carried out by the social aesthetic. The product design needs not only to embody the functionality of the product, but also to the inheritance of cultural spirit, and to pay more attention to people's sense of identity and belonging to the culture. Based on the three-level theory of emotional design proposed by Professor Donald Arthur Norman, this paper analyzes its specific application in the design of cultural and creative products, in order to establish the emotional design criteria of cultural and creative products centered on user experience. It aims to help consumers establish a sense of design identity and cultural identity for cultural and creative products, and put cultural confidence into practice.
\end{abstract}

\section{Introduction}

With the affirmation and promotion of cultural and creative industries in the opinions of the State Council on promoting the integration and development of cultural creativity and design services and related industries (GF [2014] No. 10) issued by the State Council on February 26, 2014, vigorously developing cultural and creative industries has become an inevitable choice for the transformation of national economic growth mode. As an important branch of cultural and creative industry, cultural and creative products have been widely concerned and promoted by the society in recent years. However, with the rapid development of the domestic cultural and creative market, many practical problems have emerged, such as the serious homogenization of cultural and creative product design in recent years, the limitations of product categories, and the low age of cultural orientation. The attitude of consumers towards cultural and creative products has gradually evolved from "novelty, love to pay for it" to "feel interesting, but just look around and leave" The highly competitive cultural and creative product market puts forward higher requirements for designers, that is, good cultural and creative product design should be the result of the integration of spiritual culture and material culture. It not only pays attention to the functionality of the design, but also emphasizes the humanistic care and emotional expression in the design [1].

\section{Emotion engagement is essential in cultural creative product design}

Cultural and creative products refer to the creative transformation of cultural content into design elements by taking national and regional cultural resources as the main elements, through people's wisdom and inspiration, and in combination with the production methods of technology, science and technology, and industrialization, using the expression and thinking mode of modern design, to find a new form of cultural content that conforms to the life form of modern people and create a full life A new product that meets the spiritual needs of people and meets the aesthetic requirements of modern people [2]. Cultural and creative products not only have the practical function of products, but also more importantly, the spiritual culture contained in them, which brings convenience to people's life, and at the same time, it also gives people a sense of cultural identity and belonging. Consumers purchase cultural and creative products not only to meet the functional needs, but also to focus on the cultural connotation of the products to bring consumers' psychological feelings, resulting in ideological Association, migration and understanding [3].

Cultural and creative product design is not only the subversion of tradition and the break of conventional thinking, but also the extension and supplement of practical functions of products. It is an innovation on both spiritual and material levels to integrate traditional

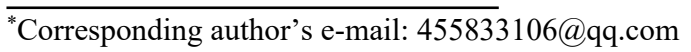


culture, environmental protection concept and fashion experience, and interpret the designer's design ideas with the goal of meeting the needs of life, focusing on the combination of emotion and rationality [4]. However, in order to build a good bridge between materiality and spirituality, the input of emotional design is an essential enhancer.

\section{Emotional design of cultural and creative products based on user experience}

Professor Donald Arthur Norman, a famous cognitive psychologist in the United States, put forward that human emotion can be divided into three levels: instinct level, behavior level and reflection level according to brain activity level in 3-emotional design of design psychology [5]. Instinct level emotion emphasizes the initial and most intuitive feeling that the product brings to the user, which has a direct relationship with the product's shape, color, material, etc. The emotion of behavior level is related to the experience that the product brings to the user, including the function, performance and usability of the product. The emotion of reflection level refers to the user's thinking after experiencing the product or receiving the service, which is directly affected by the user's personal memory, experience and cultural background. Instinct level and behavior level only contain emotional response, which is the feeling and experience that users get from the products they see or are using, and is the "present tense". On the other hand, there are cognitive and conscious changes on the basis of emotion in the level of reflection, which goes beyond other levels and lasts for a long time. Through reflection, users can often recall the past or imagine the future [6]. It can be seen that these three levels are interrelated and influence each other, and the emotion of reflection level is the most complex. As the main control level of emotion, it dominates the design style of instinct level and behavior level.

\subsection{Visceral level}

The design of cultural and creative products is particularly important in the emotional expression of instinct level. It brings consumers the initial impression of the product, which determines whether users can have feelings about the product. As a non rigid commodity, cultural and creative products have three possibilities for consumers to purchase: as a companion gift to relatives and friends; as a souvenir after visiting here; as a self appreciation of some emotional memories. Based on these three possibilities, the modeling, color and material technology in the design of cultural and creative products can be analyzed as three factors that affect people's emotional needs.

First of all, for users, "small and refined" is the best choice for cultural and creative products. Products with large volume and hard to carry will be the obstacles for tourists to choose at first, and also emotionally unfriendly. The product is small in shape, which can take into account the convenience of carrying and easy to pack. Such a design will undoubtedly make consumers feel intimate and willing to learn more about the design connotation of the product. At the same time, as a cultural and creative product, it can obviously reflect the cultural characteristics in its modeling, and also requires the designer to make creative design with heart. The way of simply pasting cultural elements on different product carriers has been widely used, and initially achieved results in the market, but in the long run, such a design method is undoubtedly an obstacle to the progress of the cultural and creative product market and has brought aesthetic fatigue to users.

Secondly, color, as one of the language of emotional expression in cultural and creative product design, can not only meet people's basic aesthetic needs, but also stimulate consumers' curiosity and desire for further understanding of the product. Different colors can cause people different feelings and associations, and thus produce different emotions. Different regions, different nationalities and cultures have different preferences for color. Using the representativeness of color to strengthen the cultural representativeness of cultural and creative product design, so that consumers are attracted by its unique or representative color, and produce pleasant or excited emotions. Such cultural and creative product design is a successful design.

Thirdly, materials, as one of the important media of emotional expression of products, bring people a kind of memory emotional cognition. For example, wood and bamboo bring people a kind of natural emotional experience, while metal gives people a noble and beautiful feeling. Therefore, when choosing materials, the designers of cultural and creative products should not only consider the physical properties of materials, but also pay attention to the physical and psychological feelings brought by materials. By selecting appropriate materials, the perceptual components of products should be increased, and the products should be endowed with appropriate cultural characteristics [7]. Here, the product process is more inclined to product quality or quality. At present, there are many rough and indiscriminate cultural and creative products in the market, with poor quality and low price. To a large extent, it has lowered the height of the entire cultural and creative product market and brought unpleasant user experience to consumers.

\subsection{Behavior level}

The emotional experience at the behavioral level pays more attention to the usability of the product and meets the user's demand for the functionality and ease of use of the product. As the famous Japanese product designer Naoto Morizawa said, "you don't need to use a manual to tell people how to use it. It must only feel that people can use it naturally." It is the core of emotional investment in cultural and creative design to let consumers have a sense of pleasure at the behavioral level when using or experiencing cultural and creative products, and deepen the understanding of cultural connotation while using 
products happily. The following aspects can be considered in the design.

First of all, add interest to the use of cultural and creative products. In line with the user's use behavior, cultural elements are cleverly integrated into the use process of the product, so that consumers can understand the culture while experiencing the product, and deepen their understanding of the culture. "Magic cube of the Six Dynasties", once awarded the title of "top ten most popular cultural and creative products of Chinese cultural and creative industries", is a characteristic cultural and creative product of Nanjing Museum of the Six Dynasties. The six aspects of the Six Dynasties are cleverly combined with the Six Dynasties of the eastern $\mathrm{Wu}$, the Eastern Jin, the song, Qi, Liang and Chen, so that the participants can be familiar with the Six Dynasties' names while playing the magic cube, and arouse the users' strong interest in exploring the Six Dynasties' culture of Nanjing (Figure 1).

Secondly, increase the user's participatory experience. Experience originates from interaction and is the result of interaction between people and objects. The more

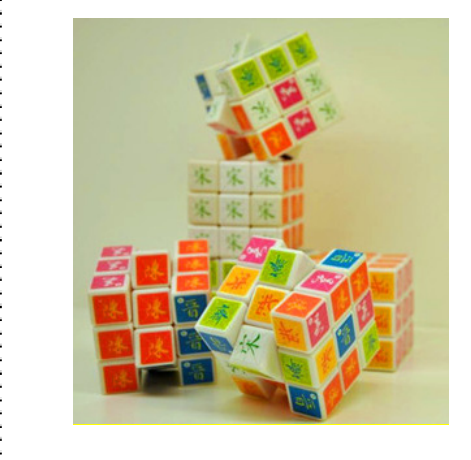

Figure 1. Six Dynasties cube

\subsection{Reflection level}

Cultural and creative products, as a kind of spiritual and cultural products with practical functions, when consumers choose cultural and creative products, they pay more attention to the needs of spiritual consciousness rather than the material level. The emotional needs of the reflective layer are particularly critical in the design of cultural and creative products. It gathers the spiritual and cultural communication and emotional sublimation, which is the soul of cultural and creative products. If you want to do a good job in the emotional design of reflection level, you can start from the following aspects.

First of all, trigger emotional memory. Emotional memory refers to people's deep and unforgettable feelings towards the familiar characters, things and environment in the past. In the fast-paced modern life, most people are busy making a living and forget the precious memories buried in the deep memory. These emotional memories may be related to consumers' cultural background, life customs, characteristics of a certain era, or contain different life stories and emotional forms of interaction, the richer experience and emotion [8]. In the process of participating in the experience of products, users will integrate their preferences, experience or emotional factors into the use of products. In this process, the personality and emotion of consumers are fully displayed, and the emotional experience degree is greatly increased. As a cultural and creative product of Nanjing Ming city wall, Happy Sand, which is a DIY model toy for space sand of Nanjing city wall, is a successful design case with strong user participation experience. The product design aims at the growing children, and designs the most representative buildings of Nanjing Ming city wall as toy sand models, so that children can play with sand while they play with Nanjing City Wall culture and culture Curious about the history of the city wall, parents can then tell the story of the history of the city wall of Nanjing on the cards with pictures and texts attached to the toys to help children understand the culture of the city wall of Nanjing in the Ming Dynasty (Figure 2).

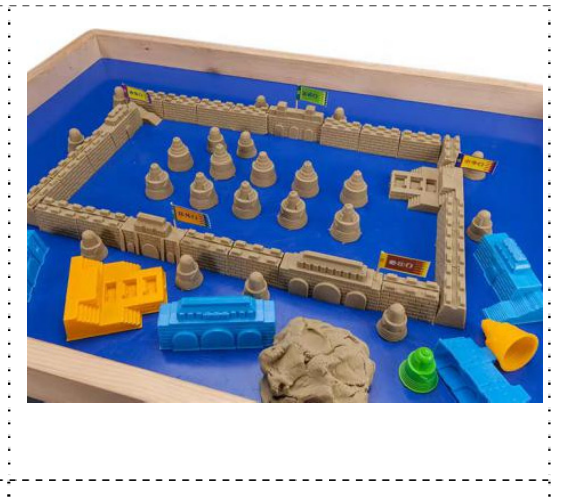

Figure 2. DIY model of Nanjing city wall -- Happy sand

experiences [9]. Putting emotional memory into cultural and creative product design can not only help users understand the cultural spirit expressed by the product, but also help users find a sense of emotional belonging after a long time of separation. As we are familiar with a wall mounted CD player designed by Naoto Fukasawa, who is the famous product designer in Japan, the "click" switch sound, whether it's hearing or feeling, will deeply recall people's memory of switching lights when they were children. With the sound of music coming from the $\mathrm{CD}$ player, people gradually fall into memories of the past (Figure 3).

Furthermore, meet the personalized needs. Personalized needs are the advanced stage of users' emotional needs. After meeting the basic emotional needs, people began to pursue unique emotional needs. The post-80s, post-90s and even post-00s have become the main force of cultural and creative market patronage. They have distinct personalities, advocate fashion and high technology, are good at accepting new things and have their own unique views. This puts forward new requirements for cultural and creative designers, that is, to design new cultural and creative products in line with the characteristics of the times. The cultural and creative 
products of Beijing Palace Museum can be said to be the leader in the field of cultural and creative product design in China. According to data, in 2015, Beijing Palace Museum has developed 8683 cultural and creative products with a turnover of more than 1 billion. Entering its Taobao cultural and creative shop, customers can find that there are many categories of cultural and creative products in the Forbidden City, breaking through the traditional categories of cultural and creative products, introducing social cutting-edge technology, new fashion favorites, etc. into the categories of cultural and creative products in the Forbidden City, and the design creativity is younger, breaking through the shackles of traditional cultural concepts, and "sprouting" historical figures, which are loved and recognized by young people. One of the cultural and creative products court beads headset has won the favor of many young people. The design cleverly selects the earphone as the carrier to transmit the culture of the Qing Dynasty, so that the original identity and status of the court beads "cross" to modern life, and become a fashion earphone for everyone to wear (Figure 4). It can be said that the integration of personalized needs makes the audience of cultural and creative products more extensive.

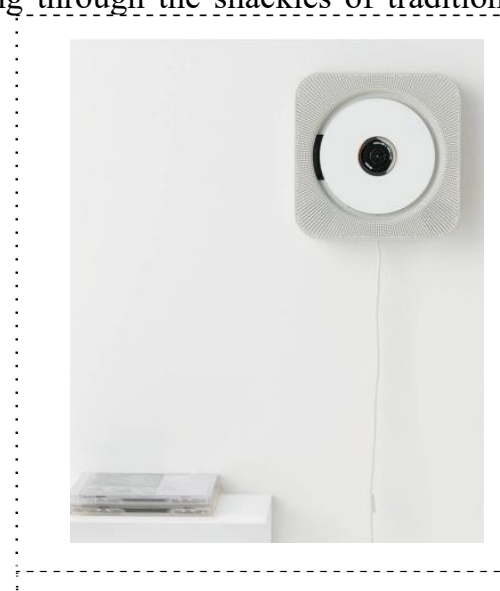

Figure 3. CD player
Last but not least, establish brand sentiment. The core of cultural and creative brand lies in the lifestyle and values it advocates. They reconstruct the relationship between people and things, spread beliefs, and establish a bond of value and trust, which has an impact on people's lifestyle [10]. Cultural and creative brands should not only deliver cultural and creative products to users, but also establish communication and connection with users in the spiritual world to bring good service and consumption experience to customers. In fact, consumers' choice to recognize a specific cultural and creative brand is an affirmation of the cultural value transferred by the brand and an identification of the cultural connotation. As the most visible cultural symbol in Taiwan, Cheng pin bookstore has become a way of life for local people. The essence behind the cultural and creative brand, which has been strengthened gradually for 20 years, is to stick to the human ideal, that is, to create a cultural atmosphere space integrating "interaction between human and space". In this cultural space, consumers are looking for a piece of cultural sentiment in their hearts.

\section{Conclusion}

The vigorous development of the cultural and creative industry calls for the arrival of a batch of cultural and creative products in line with the breath of the new era. Flexible use of the three levels of emotional design investment in cultural and creative product design can provide designers with more extensive design ideas. Through the analysis of successful cases in the design of

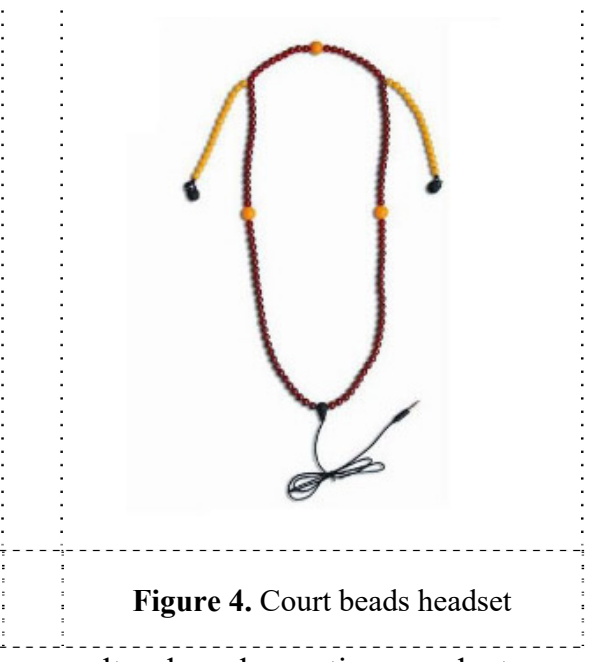

cultural and creative products, we can see that the emotional design of cultural and creative products with user experience as the center will become a sustainable development path of cultural and creative product design.

\section{References}

1. Xiaofei Tang. (2017) The function and emotional expression of color in the design of cultural and creative products. J. Packaging Engineering, 38(04):38-41.

2. Chunfeng Xie. (2020) The application of regional cultural elements in cultural and creative product design. J. Packaging Engineering, 41(08):313-316.

3. Yan Hu. (2017) On the design method and innovation of cultural and creative products. J. Art and Design (Theory), 2(08):92-93.

4. Yangxin Wang, Shanshan Xu. (2019) Research on the acquisition and innovation of traditional cultural elements in cultural and creative product design. J. Shen Hua (I), 12: 128-129.

5. Caixuan Chen. (2019) Research on the design of cultural and creative products based on emotional design. J. Famous Scenery, 05: 202-203.

6. Yanqi Shao. (2019) Rhetorical analysis of product pleasure based on emotional cognitive theory. J. Art Appreciation, 02: 220-221.

7. Hongjuan Chen. (2011) Research on the application of material emotion in product design. J. Packaging Engineering, 10:59-62. 
8. Chaoran Huang. (2018) Research on the emotional design of cultural and creative products in Domestic Museums. J. Art Appreciation, 02: 217-218.

9. Jiayun Zheng. (2018) Analysis of emotional interaction design in wearable intelligent products. J. Industrial Design, 04: 117-118.

10. Ting Shen, Daze Dong. (2017) Secrets of cultural and creative brands. Guangxi Fine Arts Publishing House, Nanning. 